\section{The role of cow milk in reducing the number of streptococcus mutans}

\author{
Irene E. Rieuwpassa, ${ }^{1 *}$ Donald R. Nahusona, ${ }^{2}$ Indah Ramadhani ${ }^{1}$
}

\title{
Abstract
}

Objective: This research aims to provide an overview of chewing gum casein effect on the number of bacteria streptococcus mutans and profile saliva. Casein is one of the elements in cow milk that has $70-80 \%$ of the total protein and function to prevent bacterium and other saliva sticking on the enamel surface of teeth. Consuming free sugar gum after eating can help to remineralise enamel, increase saliva and decrease the number of streptococcus mutans. Mouth work on mastication increases salivary flow rate. Therefore saliva production will increase and will change its acidity $(\mathrm{pH})$.

Material and Methods: The research design used was experimental research conducted in two groups where the control group by giving xylitol gum and the second group was given chewing casein gum. A total of 20 participants who match the criteria of research subjects chewed gum for 9 consecutive days and calculated the amount of streptococcus mutans, volume and $\mathrm{pH}$ of saliva.

Results: The number of streptococcus mutans bacteria experienced a decline mainly in the group 69.60 in the first day to 22.80 in the ninth day. Thus, independent examination was done and $p<0.005$ was indicated, meaning that there was significant difference of casein gum in terms of decreasing streptococcus mutans bacteria, compared with xylitol gum.

Conclusion: Casein gum made from cow milk can reduce the number of streptococcus mutans bacteria.
1Department of Oral Biology, Faculty of Dentistry, Hasanuddin University, Makassar, Indonesia 2Department of Orthodontic, Faculty of Dentistry, Hasanuddin University, Makassar, Indonesia

*Corresponding to:

Irene E. Rieuwpassa, Department of Oral Biology, Faculty of Dentistry, Hasanuddin University, Makassar, Indonesia

drgirene@yahoo.com

Received: 2 January 2018

Revised: 8 November 2018

Accepted: 25 November 2018

Available Online 1 December 2018

Keywords: Cow milk, Streptococcus mutans, pH saliva, The volume of Saliva

Cite this Article: Rieuwpassa IE, Nahusona DR, Ramadhani I. 2018. The role of cow milk in reducing the number of streptococcus mutans. Journal of Dentomaxillofacial Science 3(3): 172-176. D01: 10.15562/jdmfs.v3i3.695

\section{Introduction}

Tooth decay or caries is one of the most common diseases in the oral cavity. Caries is a process in which dental plaque develops over a period of time on hard tissue of teeth (enamel, dentine and cementum). ${ }^{1}$ Caries is caused by the interaction of four factors, ie microorganisms, carbohydrates, time and host. Microorganism is a major role in the occurrence of cavities because it adheres to the surface of the teeth and ferment carbohydrates into acids that dissolve hard tissue. ${ }^{2,3}$

There are has many products made to prevent caries. One is xylitol which is formed in toothpaste gum products, mouthwash and suction tablets. Xylitol is one of the proven ingredients to prevent caries. In a previous study, xylitol may increase saliva $\mathrm{pH}$ to prevent caries. ${ }^{4}$ Recent studies have shown that casein can prevent caries by suppressing the activity of streptococcus mutans. Casein can be obtained from cow's milk. ${ }^{5}$

\section{Material and Methods}

This research was conducted in July-August 2017. This study is a experimental research using pretestpostest with control group design. This study was conducted in Makassar involving 20 people as a sample aged between 14-16 years old and had low to moderate OHI-S index, divided into 2 (two) groups, ie treatment group (chewing gum casein) and control group (chewing gum xylitol). This research was started with OHI-S examination of the research sample and the inclusion criteria were subject with low to moderate OHI-S values. Then continued with casein isolation from cow's milk and chewing gum kasein made at Pharmacetics Laboratory of Hasanuddin University Faculty of Pharmacy. After obtaining the subject according to the inclusion criteria and the manufacture of casein gum, researchers will clean oral cavity of the sample by scalling.

Subsequently, the sample was instructed to chew the casein gum (as treatment group) and xylitol gum (as control group) for 9 days and every day to chew three times ie morning 08.00-09.00; noon 12.00-13.00; and 17:00 to 18:00 o'clock. Sampling was done using swab technique and spitting method done on day $0,3 \mathrm{rd}$, 6th and 9th. Sampling using swab technique on the upper and lower mandibular molar 1 and molar 2 teeth to calculate the amount of Streptoccus mutans microorganism. spitting method was used to calculate salivary $\mathrm{pH}$ and salivary volume. Casein chewing gum from cow's milk is chewing gum containing casein, which is obtained from cow milk isolate. Gum xylitol is a gum containing xylitol, where xylitol is one of the essential non-acididogenic and non-cariogenic 
sugar substitutes. Streptococcus mutans is one of the bacteria that cause cavities. Saliva is a complex and colorless oral fluid which consists of mixed secretions of major and minor salivary glands. The degree of saliva acidity (salivary $\mathrm{pH}$ ) is saliva acidity which can be known by using $\mathrm{pH}$ meter. Volume saliva in $\mathrm{ml}$ is the amount of saliva produced in the presence of stimuli mechanical and chemical.

The criteria for selection of sample for the presents studi were as follows: age 14-16 years, has no caries or maximal superficial carious teeth in the maxillary and mandibular upper molars, not consuming other gum and not eating 60 minutes before the research, not undergoing drug therapy, healthy body condition, willing to be a research sample, willing to follow the instructions of the researcher.

The total number of research results collected and recorded, and performed processing and data analysis. The research data were measured using paired t-test statistical analysis.

\section{Results}

Table 1 in the xylitol group showed the average number of microorganism on day 0 (pre-test) that is 60.00 and continue to decrease the number of microorganism up to 30.44 on the ninth day. In the casein group showed the average number of microorganism on day- 0 (pre-test) that is 69.60 and continue to decrease the number of microorganism up to 22.80 on the ninth day.

Thus, when compared between the xylitol group and the casein group that was most effective in reducing the amount of streptococcus mutans microorganism, the treatment group was due to the average number of microorganism on the ninth day of the treatment group was 22.80 compared to the control group of 30.44 figure 1.

Table 2 in the xylitol group the mean of salivary $\mathrm{pH}$ on day 0 (pre-test) was 7.15 then decreased mean salivary $\mathrm{pH}$ on the next day. However, the mean salivary $\mathrm{pH}$ difference on the $3 \mathrm{rd}$, 6th and 9th days did not decrease or increase. The same thing happened in the casein group, the average $\mathrm{pH}$ of saliva casein group on the day- 0 that is 7.20 which then decreased on the next day.

So when compared between xylitol group and casein group saliva $\mathrm{pH}$ average did not experience difference. However, salivary $\mathrm{pH}$ in the xylitol group and the casein group was still in a normal state of 6.9-7.2 figure 2.

Table 1 Comparison of the amount of streptococcus mutans in the xylitol group and the casein group

\begin{tabular}{lccccc}
\hline \multirow{2}{*}{ Groups } & & Streptococcus mutans (CFU) & Normality test & & Comparison test \\
\cline { 3 - 3 } Xylitol & Days & Mean \pm SD & p-value* & & p-value** \\
& 0 & $60.00 \pm 0.77$ & .51 & \\
& 3 & $38.00 \pm 0.63$ & .27 & 0.00 \\
& 6 & $32.80 \pm 0.60$ & .99 & \\
Casein & 9 & $30.44 \pm 0.16$ & .98 & \\
& 0 & $69.60 \pm 0.73$ & .79 & 0.00 \\
& 3 & $58.40 \pm 0.80$ & .47 & \\
& 6 & $33.20 \pm 0.54$ & .90 & \\
& 9 & $22.80 \pm 0.35$ & .74 & \\
\hline
\end{tabular}

Table 2 Comparison of saliva pH in the xylitol group and casein group

\begin{tabular}{|c|c|c|c|c|}
\hline \multirow{2}{*}{ Groups } & \multirow[b]{2}{*}{ Days } & \multirow{2}{*}{$\begin{array}{c}\text { Saliva pH } \\
\text { Mean } \pm \text { SD }\end{array}$} & \multirow{2}{*}{$\begin{array}{c}\text { Normality test } \\
\text { p-value* }\end{array}$} & \multirow{2}{*}{$\begin{array}{c}\text { Comparison test } \\
\text { p-value }{ }^{* *}\end{array}$} \\
\hline & & & & \\
\hline \multirow[t]{4}{*}{ Xylitol } & 0 & $7.15 \pm 0.08$ & .36 & \multirow{4}{*}{0.00} \\
\hline & 3 & $6.96 \pm 0.11$ & .90 & \\
\hline & 6 & $6.89 \pm 0.05$ & .51 & \\
\hline & 9 & $6.96 \pm 0.04$ & .64 & \\
\hline \multirow[t]{4}{*}{ Casein } & 0 & $7.20 \pm 0.12$ & .72 & \multirow{4}{*}{0.00} \\
\hline & 3 & $6.59 \pm 0.06$ & .96 & \\
\hline & 6 & $6.82 \pm 0.12$ & .78 & \\
\hline & 9 & $6.92 \pm 0.07$ & .65 & \\
\hline
\end{tabular}


Table 3 Comparison of Saliva volume in xylitol group and casein group

\begin{tabular}{lcccc}
\hline \multirow{2}{*}{ Groups } & & Saliva volume $(\mathbf{m l})$ & Normality test & Comparison test \\
\cline { 3 - 4 } Xylitol & Days & Mean \pm SD & p-value* & .25 \\
& 0 & $3.38 \pm 0.36$ & .31 \\
Casein & 3 & $4.20 \pm 0.84$ & .69 \\
& 6 & $5.20 \pm 0.15$ & .69 \\
& 9 & $6.70 \pm 0.15$ & .81 \\
& 0 & $3.30 \pm 0.57$ & .78 \\
& 3 & $4.10 \pm 0.74$ & .83 \\
& 6 & $5.20 \pm 0.91$ & .31 \\
\hline
\end{tabular}

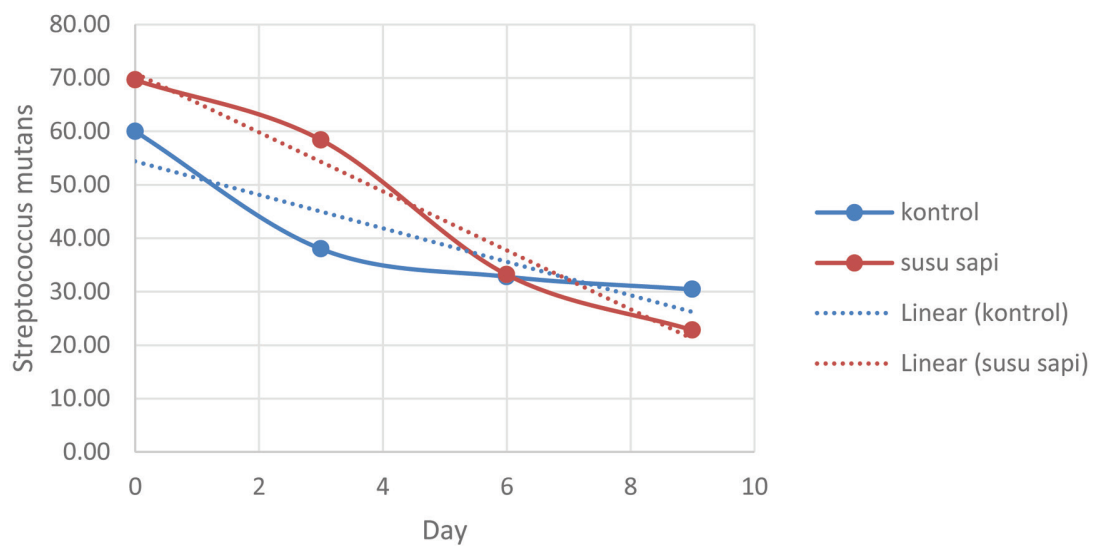

Figure 1 Graph of the difference in the number of streptococcus mutans bacteria in the control group and the treatment group

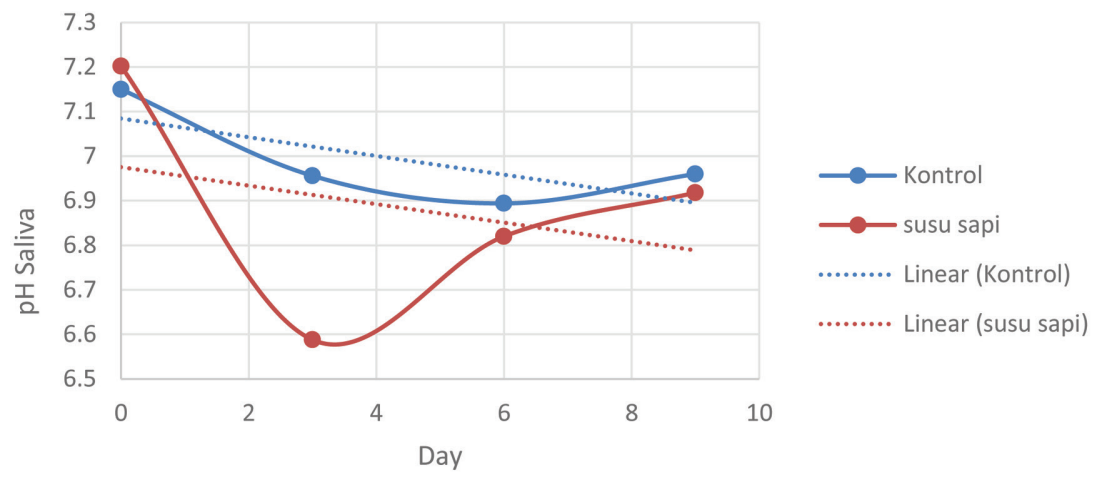

Figure 2 Graph of salivary $\mathrm{pH}$ difference in control group and treatment group

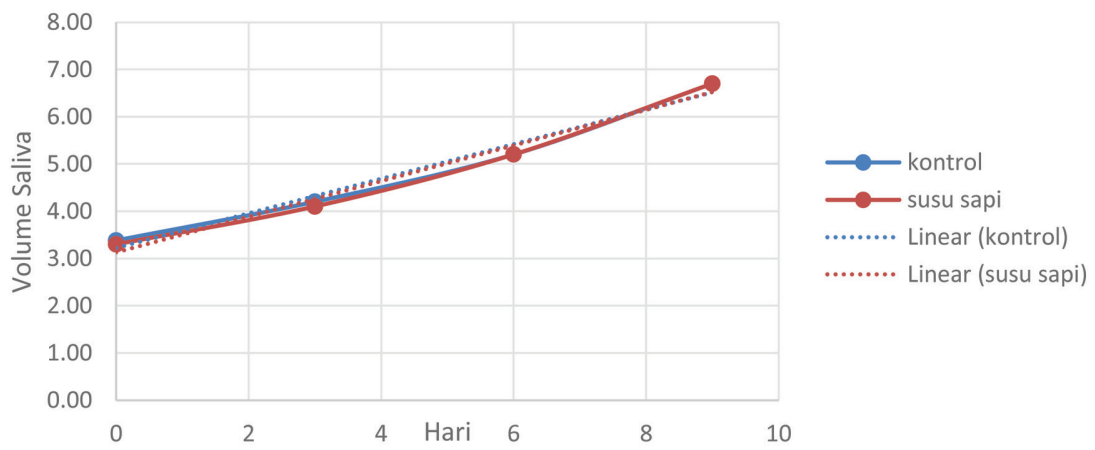

Figure 3 Graph of salivary volume difference in the control group and treatment group
Table 3 in the xylitol group the average salivary volume on day 0 (pre-test) was 3.38 and then continued to increase the average saliva volume up to 6.70 on the ninth day. In the casein group also showed an average increase of salivary volume on a daily basis of 3.30 on days 0 to 6.70 on the ninth day.

So that the xylitoll group and the casein group have the same ability to increase salivary volume. This is because the average saliva volume in the xylitol group and the casein group continued to increase the salivary volume and the average saliva volume on the ninth day was also the same ie 6.70 figure 3.

\section{Discussion}

This research is true experimental research which aims to know the influence of chewing gum from cow milk to the amount of streptococcus mutans bacteria, saliva $\mathrm{pH}$ and salivary volume. Based on saliva $\mathrm{pH}$ in the control group and treatment group. The increase in salivary volume in this study is a growth hormone that is influenced by chemical and mechanical stimuli. Thus, an increase in salivary volume will be followed by an increase in salivary $\mathrm{pH}$. Based on other studies conducted stating that chewing gum xylitol quickly increases salivary flow rate because it is a combination of stimulus and mechanical stimulus. ${ }^{6,7}$

The results showed that there were differences in the amount of streptococcus mutans bacteria, salivary $\mathrm{pH}$ and salivary volume on the 0 th, 3rd, 6 th and 9th days. The samples were divided into two groups: control group (chewing xylitol gum) and treatment group (chewing on casein gum).

Streptococcus mutans, saliva $\mathrm{pH}$ and salivary volume are among the factors that lead to caries. Streptococcus mutans is a bacterium normally obtained in the oral cavity. However, in special conditions, these bacteria can be opportunistic pathogenic bacteria that can damage the host. Based on existing research indicates that the bacterium 
streptococcus mutans is a bacteria that play a role in the beginning (initition) in the occurrence of caries, so that required a material to prevent the bacterial attachment. ${ }^{2,3,8}$

Saliva $\mathrm{pH}$ and salivary volume are the host factors that cause caries. saliva in the oral cavity has a function, namely: cleansing of bacteria; buffer action; antibacterial; and remineralization. In this study, salivary secretion is obtained by a simple reflex from chewing gum that normally amounts in the stimulus range from 3-4 $\mathrm{ml} / \mathrm{min} ., 9,10$

The influence of chewing gum casein from cow milk to the amount of streptococcus mutans bacteria because it can reduce the number of bacteria. In addition, the casein chewed gum from cow's milk was more effective than xylitol gum because the number of bacteria on the ninth day for the chewing sample of less casein gum was cheaper than the sample chewing xylitol gum. ${ }^{11,12}$

This is consistent with research conducted by Vacca-Smith et al. Which has proved that casein prevents bacterial attachment and salivary components on enamel and pellicle surfaces and reduces glucosyl transferase activity, thus reducing glucose formation and plaque attachment. ${ }^{12}$

The graph of salivary $\mathrm{pH}$ differences in the control group and the treatment group showed that casease chewed gum from cow's milk has the same ability as xylitol gum as it can neutralize salivary $\mathrm{pH}$. On the third day, however, salivary $\mathrm{pH}$ in the treatment group experienced a dramatic decline of 6.6 but returned to normal on the sixth and ninth day. This may be due to the difference in $\mathrm{pH}$ of the sample between one individual to another and the condition of the oral cavity and the condition of one's health. One example based on existing research sample is the period of menstruation either pre or post experienced by a woman. Based on the research conducted by Syamsudduha et al showed that there are differences in saliva $\mathrm{pH}$ in pre-menstruation female adolescents compared with post-menstrual women adolescents. ${ }^{13,14}$ Other factors that may affect the non-compliance of the sample of instructions that have been described.

The graph of salivary volume difference in the control group and the treatment group showed that casease chewed gum from cow's milk has the same ability as xylitol gum because it can increase saliva volume on the 0th day until the ninth day. Based on the results of the study showed that the increase of salivary volume followed by saliva $\mathrm{pH}$ in the control group and treatment group. The differences in salivary flow rate and $\mathrm{pH}$ that is influenced by chemical and mechanical stimuli. From the results of this study, found an increase in $\mathrm{pH}$ after mechanical stimulus and decrease after chemical stimulus. Thus, an increase in salivary flow will be followed by an increase in salivary $\mathrm{pH}$. Based on other research conducted by Polland et al. ${ }^{7}$ stated that chewing gum xylitol rapidly increases salivary flow rate because it is two combinations of flavor stimulus and mechanical stimulus. ${ }^{15,16}$

This research found that xylitol and casein gum had the same ability to increase salivary volume and neutralize salivary $\mathrm{pH}$. This is because gum xylitol and casein gum have two combinations that can stimulate salivary secretion that is combination of taste stimulus and mechanical stimulus. ${ }^{7}$

That casease gum and xylitol gum have the same ability to increase salivary volume and neutralize salivary $\mathrm{pH}$. This is because chewing gum xylitol and casein gum have two combinations that can stimulate salivary secretion that is a combination of taste stimulus and a mechanical stimulus. ${ }^{16}$

That casein gum is more effective in reducing the amount of streptococcus mutans bacteria than xylitol gum. This is because the content of casein gum chewing casein from cow's milk is able to prevent the attachment of bacteria and salivary components on enamel and pelikel surfaces and reduce the activity of glucosyltransferase. In addition Weiss and bibby have demonstrated the most effective protection of milk that is the content of casein capable of being a buffer system. ${ }^{11,12}$

However, it shows that casein gum is more effective in reducing the amount of streptococcus mutans bacteria than xylitol gum. This is because the content of casein gum chewing casein from cow's milk is able to prevent the attachment of bacteria and salivary components on enamel and pelikel surfaces and reduce the activity of glucosyl transferase. In addition Weiss and bibby have demonstrated the most effective protection of milk that is the content of casein capable of being a buffer system. ${ }^{11,12}$

\section{Conclusion}

Based on the research that has been done then it can be concluded that: casein gum from cow's milk is effective in decreasing the amount of streptococcus mutans that is with the number of microorganism on day 0 as much as $69.60 \mathrm{cfm}$ to $22.80 \mathrm{cfm}$, casein gum has the same ability as xylitol gum in maintaining salivary $\mathrm{pH}$, casein gum has the same ability with xylitol gum in increasing salivary volume.

\section{Acknowledgment}

The author would like to express sincere thanks to all students of the Faculty of Dentistry, Hasanuddin University for providing active participation during this research process. 


\section{Conflict of Interest}

The authors report no conflict of interest.

\section{References}

1. Heymann HO, Swift EJ, Ritter AVR. Sturdevant's art and science of operative dentistry. St Louis: Elsevier; 2013. p. 41-48.

2. Anggraeni Dewi, Tjahajawati Sri, Wihardja Rosy. Saliva secretion difference before and after rising with baking soda on monopose woman. J Dentist 2013:57: 28-33.

3. Emamieh shila, Hossein Goudarzi, Alireza akbarzadeh, Yosra khaterizadeh. Comparison of the effect of recaldent and xylitol on the amounts of salivary streptococcus mutans. Novelty Biomedic 2015;1: 33.

4. Elsayad I, Sakr A, Badr Y. Combining casein phosphopeptide-amorphous calcium phosphate with fluoride: synergistic remineralization potential of artificially demineralized enamel or not. J Biomed 2009;14: 20-28.

5. Puy, Carmen L. The role of saliva in maintaining oral health and as an aid to diagnosis. Med Oral Patol Oral Cir Bucal 2006;11: E449-E455.
6. Polland KE, Higgins F, Orchardson R. Salivary flow rate and $\mathrm{pH}$ during prolonged gum chewing in humans. J Oral Rehab 2013;30: 861-865.

7. Morgan MV, Adams GG, Bailey DL, et al. The anticariogenic effect of sugar-free gum containing CPP-ACP nanocomplexes on approximal caries determined using digital bitewing radiography. Caries Res 2008;42: 171-184.

8. Galhotra Virat, Anjali sofat, Harpett dua, Sushant Rohila. Anticariogenic and cariostatic potential of components of diet. Indian J Dent Sci 2014;6: 79-85.

9. Londhe VP, Gavasane AT, Nipate SS, et al. Role of garlic (allium sativum) in various diseases: an overview. J Pharmaceutic Res \& Opinion 2011;1: 129-134.

10. White AJ, Gracia LH, Barbour ME. Inhibition of dental erosion by casein and casein-derived proteins. Caries Res 2011;45: 13-20.

11. Johansson I, Holgerson LP. Milk and oral health. Nestle Nutr Workshop Ser Pediatr Program 2011;67: 55-66.

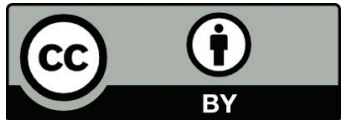

This work is licensed under a Creative Commons Attribution 